\title{
Análisis del tratamiento informativo en noticias de televisión. Estudio de caso de la huelga de profesores en España y Perú
}

\author{
Recibido: 29 de noviembre de 2013 \\ Aceptado: 26 de junio de 2014 \\ Publicado: 28 de noviembre de 2014
}

\author{
Fernando Morales Morante \\ fernando.morales@uab.es
}

Universidad Autónoma de Barcelona (España)

\begin{abstract}
Resumen: En el presente artículo se analizan y comparan los rasgos culturales y audiovisuales que determinan los estilos y el tratamiento informativo de una noticia de contenido similar, emitida por dos medios privados de distinto país: Perú y España. El estudio se realiza aplicando el protocolo del Modelo de Construcción Informativa Eficaz (MOCIAE) y detecta una claro sesgo en favor de la postura gubernamental en ambos países. No obstante, mientras en el caso español se detecta mayor presencia de elementos formales de puesta en escena y multiperspectiva de opinión; en la versión peruana se constata un tratamiento y enfoque menos textual y predominantemente espectacular, basado en el uso de recursos de sonido ambiental y las acciones violentas de los manifestantes.
\end{abstract}

Palabras clave: Noticia, información, eficacia comunicativa, Perú, España.

\begin{abstract}
This article analyzes and compares the cultural and audiovisual features that determine the styles and informative treatment of similar news content, issued by two private means different country: Peru and Spain. The study was made using the protocol Fact Efficient Model Construction (MOCIAE) and detects a clear bias in favor of the government's position in both countries. However, as in the Spanish case increased presence of formal elements of staging and multiperspective opinion, the Peruvian version is detected finds treatment and focus less textual and predominantly spectacular, based on the use of resources ambient sound and the violent actions of the protesters.
\end{abstract}

Key words: News, Information, Communication Effectiveness, Peru, Spain. 


\section{Introducción}

Las diferencias sensibles en cuanto al tratamiento informativo entre los medios de comunicación deja entrever que su sentido y posicionamiento frente a los hechos representados viene fuertemente influenciado por directrices editoriales, que imponen un determinado estilo y una orientación a favor o en contra del o los protagonistas del hecho representado, así como por una mayor preocupación por darle un tratamiento naturalista o espectacular.

La digitalización ha traído consigo nuevas herramientas para agilizar y mejorar la construcción y emisión de noticias, entrevistas y reportajes audiovisuales. Todos estos recursos además de optimizar los procesos productivos en términos de ahorro de tiempo y economía del equipo humano, son a su vez oportunidades para articular mejor el contenido de los mensajes, potenciar su eficacia e incrementar su impacto periodístico y su capacidad de competitividad con el resto de cadenas de televisión. Sin embargo, aun cuando estos componentes sean siempre comunes y extrapolables, podemos advertir también enfoques y estilos particulares cuando comparamos el tratamiento de noticias de un mismo tema en canales de diferentes países o culturas.

\section{Objetivos}

El presente artículo se plantea los siguientes tres objetivos de investigación:

- Definir los rasgos formales y estructurales que definen la expresión informativa y estética de dos noticias televisivas de una misma temática, producidas y emitidas en España y Perú, respectivamente.

- Efectuar un análisis comparativo del tratamiento periodístico de una noticia para la televisión (Huelga de Maestros) difundida por dos cadenas de televisión: Televisión Española y Panamericana TV, a partir de la aplicación del Modelo de Construcción Informativa Audiovisual Eficaz (MOCIAE) (Morales, 2010a).

- Establecer, a partir del resultado del análisis, los elementos característicos que tipifican el tratamiento del contenido, la forma externa y la manera particular cómo dichos rasgos son tratados y presentados al televidente por ambas cadenas y según patrones estilísticos, programáticos y culturales distintos.

\section{Marco teórico}

\subsection{El mensaje-noticia como proceso y estructura}

Según las rutinas prácticas de redacción periodística (Huertas y Perona, 1999; Diez y Abadía, 1998; Van Dijk, 1990), la elaboración de noticias para la televisión se efectúa controlando 
principalmente dos niveles de estructuración de la información, la macroestructura o "coherencia semántica global” y la microestructura o "coherencia sintáctica".

La primera hace referencia a cómo los elementos que componen un texto permiten deducir al lector o escucha que las diferentes partes forman un todo (Huertas y Perona, 1999). Según Van Dijk (1990: 47), la macroestructura define no sólo lo que denominamos la organización temática del texto, sino también su coherencia global. Por ejemplo, si el texto incluye proposiciones que no pueden subsumirse bajo un tema determinado o nuevo en una conversación, podemos decir que el hablante es incoherente o que no se atiene al tema del cual está hablando. Supone ordenar la información en bloques, apartados y conclusiones elegidos según su nivel de relevancia (Cassany, 1987).

Por su parte, la microestructura o coherencia sintáctica, consiste en la concordancia existente entre las palabras y la relación entre las frases que componen cada una de las unidades subordinadas del mensaje, sea este escrito o audiovisual (Huertas y Perona, 1999: 51). Según Westley y MacLean (1957), el periodista desarrolla tres fases diferentes para articular este discurso: a) Gatekeeper, donde se selecciona la información o discurso informacional; b) redacción del texto o discurso textual; y c) la locución de la noticia o discurso oral.

Para el caso de la televisión, nosotros añadiríamos una cuarta fase: "discurso audiovisual", en la cual los elementos de la coherencia textual, se registran y exhiben a través de dos corrientes: imagen y sonido (May y Barnard, 2003; Sadosky y Paivio, 2001), añadiendo así una corriente significativa dual. En esta línea, Mas (2011) configura un modelo de noticia para la televisión articulando tres niveles: informativo, estructural y superestructural, desarrollando una propuesta mejorada de la teoría estructural compleja (Taboada y Mann, 2005) que sugiere también diferentes tipos de discurso en función del tipo de asociación de la información: "núcleo" o "satélite" a partir del grado de novedad que representa la información para el receptor".

\subsection{Base estructuralista de la noticia de televisión}

La matriz estructuralista de los mensajes informativos tiene su raigambre en los géneros narrativos y dramáticos más antiguos. El paradigma ternario clásico: presentación, nudo y desenlace, propio de las historias argumentales (Chion, 2001, 143; Quinquer, 2001: 133; Field, 2001: 117), se modela para establecer una organización dosificada de la información en bloques, escenas y secuencias, tal como se organizan las películas y los programas

\footnotetext{
1 En consecuencia, el control de ambos niveles de estructuración del mensaje (coherencia semántica y coherencia sintáctica) regula la construcción de un orden temático y jerárquico de los datos, fundamental para que el receptor ejecute una lectura e interpretación certera de los hechos representados en la pantalla. Si el texto, las imágenes y sonidos poseen un ordenamiento adecuado (y cada una de sus partes mantiene una sucesión interna lógicamente organizada) será claro, preciso y coherente para el receptor (cf. Morales Morante, 2012).
} 
de televisión. Este esquema es igualmente aplicable a la estructuración de las noticias. Cebrián (1998: 201) articula la noticia en cuatro partes: cabecera, desarrollo, transiciones internas y cierre. Prado (1981: 49) la condensa en tres: entrada, cuerpo y cierre. La forma estructural y su extensión refleja la manera cómo se profundiza y desmenuzan los hechos en bloques de información adaptados a formatos comunicativos específicos.

\subsection{Teoría del framing o encuadre}

Las teorías del framing ("encuadre") actúan como una extensión natural de la teoría de la agenda-setting (Entman, 1993; 2009), que tiene sus primeros antecedentes en la psicología y define la existencia de un tratamiento interno y particular de la noticia (enfoque), independiente del la distribución temática en bloques del informativo. Esta tendencia que ha venido creciendo con el paso de los años (Scheufele, 1999 y 2000) propone un paradigma propio que asume que las noticias no son otra cosa que una representación de la realidad realizada por el periodista, lo que va a implicar un determinado enfoque o encuadre (frame) (Goffman, 1974).

Tankard (cf. 2001: 98) plantea tres vías o caminos para explicar la metáfora del framing:

- Los encuadres actúan como "marcos de una fotografía o una pintura" (picture frame), en tanto que aísla cierto material y centra la atención sobre el objeto representado, el cual tiene una configuración particular, en la que está implícito cierto acto de selección (qué se retrata), énfasis (cómo y con cuánto detalle se retrata) y exclusión (de otras realidades que no aparecen representadas).

- Actúan como el marco de la pintura, al fijar un tono para el visionado de la propia pintura; al igual que los encuadres noticiosos suministran un contexto interpretativo a partir del cual se juzga la historia informativa.

- El encuadre noticioso actuaría como el marco de una ventana en un edificio (elemento central de la planificación de una construcción), es decir, es una idea organizadora central para construir la información periodística.

A partir de lo dicho, se define el encuadre noticioso como "la idea organizativa central del contenido de las noticias, que proporciona un contexto y presenta el asunto a través del uso de la selección, énfasis, exclusión y elaboración" (ibídem: 100).

En esta dirección, Entman (1993: 52) añade que el proceso de encuadrar significa seleccionar "algunos aspectos de la realidad percibida, haciéndolos más sobresalientes en el texto comunicativo, de tal manera que consigan promover una definición del problema particular, una interpretación causal, una evaluación moral y/o una recomendación de 
tratamiento para el asunto descrito". Entman se centra en la idea de que los encuadres ofrecen una serie de perspectivas sobre el asunto tratado, a través de los cuales se interpretará la información.

En este sentido, los encuadres noticiosos constituyen una herramienta, utilizada por aquellos que tienen poder para transmitir informaciones a los demás, y conseguir así transformar su forma de pensar, determinando cómo debemos pensar sobre los temas ya establecidos por la agenda de los medios (Reese, 2007). Semetko y Valkenburg (2000) crearon y validaron una herramienta de testeo de cinco encuadres noticiosos: la atribución de la responsabilidad, el conflicto, interés humano, las consecuencias económicas y la moralidad.

\subsection{El Modelo de Construcción Informativa Audiovisual (MOCIAE)}

Es un esquema diseñado para efectuar un seguimiento en cada una de las fases del proceso de producción periodística de televisión. El modelo define las decisiones y procedimientos empleados para el control de la cobertura, estructuración, edición y emisión de las piezas informativas (Morales, 2010a). Con esta herramienta es posible controlar en su totalidad y de manera eficiente la elaboración, el tratamiento y la puesta en pantalla del material audiovisual noticioso, permitiendo así calcular la carga del contenido, la orientación de la información, los rasgos que definen su estructura y forma externa. Este sistema, además, permite comparar fácilmente dos o más noticias. Posee tres niveles y distintas fases de aplicación:

\subsubsection{Proceso de producción informativa}

Compuesto por cada una de las etapas convencionales de la producción informativa audiovisual: desde el registro de la información hasta la etapa de la emisión o propagación de la noticia o producto terminado. Este proceso se divide en cuatro fases:

- Cobertura: Consiste en el registro de imágenes y sonidos por el periodista/ camarógrafo en el lugar de ocurrencia del hecho noticioso ${ }^{2}$.

- Estructuración: Se examina y valora el material registrado para adecuarlo a las normas y convenciones del formato de emisión. Se pondera el grado de novedad, amplitud, interés noticiable y magnitud ${ }^{3}$.

\footnotetext{
2. En el campo, se elije el "punto de vista" o colocación de la cámara respecto de la acción, para efectuar un registro audiovisual acorde con lo que acontece en la realidad; se genera el "registro del material": planos, tomas, audio, material de apoyo, etc. Luego se elabora el "registro de testimonios" de los actores del acontecimiento, para ampliar, contrastar y profundizar los datos audiovisuales recogidos por el periodista. Puede incluirse un stand-up del reportero frente a cámara, a manera de entrada o cierre de la noticia como evidencia directa de su presencia en escena ( $c f$. Morales Morante, 2012).
}

3. Aquí se visiona el material, estableciendo una jerarquización de las diferentes partes o secciones del material producido, adecuándolo a los lineamientos estipulados (framing). Se define la estructura global y el predominio 
- Edición: Implica el modelado audiovisual de la noticia según las decisiones y criterios estructurales definidos en las dos etapas preliminares. El periodista, acompañado del editor periodístico y el montador, organiza el material disponible y construye la noticia ${ }^{4}$.

- Emisión: Se redefinen los tiempos y los criterios de ajuste sobre la base de los imprevistos y cambios producidos en la estructura del informativo, atendiendo a la llegada de otras noticias más importantes ${ }^{5}$.

En este primer nivel de construcción de la noticia se limita prácticamente a ejecutar las diferentes etapas de su realización como pieza audiovisual, siguiendo el mismo proceso de otros discursos no informativos como programas de ficción, spots publicitarios, entre otros. Sin embargo, como es bien sabido, las funciones del periodista tienen incidencia directa en decisiones más complejas respecto del tratamiento de los contenidos y su forma de presentarlos ( $c f$. Morales Morante, 2012). La ejecución de estas acciones se produce en un segundo nivel de articulación de la información.

\subsubsection{Intención informativa}

La actividad se concentra en la producción de efectos de sentido más elevados a la simple estructura formal. Para conseguirlos, se trazan dos acciones: narrar y emocionar. La primera se restringe únicamente al rol estrictamente informativo del mensaje, persigue transmitir

de unos elementos sobre otros (locuciones, testimonios stand-up, sonidos de ambiente, efectos de librería, etc.) según su extensión-importancia (tiempo) y momento de aparición. Estos criterios siguen habitualmente los modelos de análisis del texto de acuerdo con las teorías del montaje y de la teoría de la retórica (Mann y Thompson, 1988; Amiel, 2005: 27; Mitry, 2002: 426). En esta fase se elaboran los textos para ser locutados por el periodista. El tratamiento de la construcción textual ha de ser claro, conciso y directo (Martínez Albertos, 1989), para garantizar la comprensión del sentido de la información.

4. Para lograr ello, se sigue secuencialmente tres subetapas operacionales precisas (Morales, 2000: 18; Millerson, 2001: 141). La selección consiste en la elección de imágenes y sonidos atendiendo a su contenido periodístico y de combinación con el resto de sustancias icónico-auditivas; luego se realiza el ordenamiento u organización secuencial de la información, mediante dos modalidades principales: la primera, siguiendo la misma cronología del registro; es decir, de la ocurrencia de los acontecimientos; o bien apelando a recreaciones espacio-temporales que faciliten mejor la explicación de los hechos. Finalmente, la tercera etapa consiste en la elección de la duración de los fragmentos. El ajuste técnico para interconectar cada uno de los planos y sonido aprovechables, dándoles un tiempo exacto de exposición para formar transmitir el mensaje del informante, así como una estructura ágil y dinámica para el espectador.

5. Durante la emisión, también se insertan los títulos y créditos a la noticia, para definir los datos de lugar, hora, nombre de las personas figurantes, entre otros; y situar más claramente los referentes de la cobertura y la presentación en el plató. Finalmente la tercera fase de la emisión consiste en la sonorización en directo de la noticia. Aunque esta etapa se realiza de habitualmente de manera previa y externa durante la postproducción, puede hacerse también durante la emisión en directo del informativo. Cumple la función de fortalecer el sentido y la carga expresiva del discurso así como para la construcción de atmósferas a través de las cuales el mensaje puede hacerse más explicito en su sentido y carácter con el uso de otros recursos: sonido ambiente, música y efectos, etc. (cf. Morales Morante, 2012). 
los hechos de forma lineal, concatenada y producir un significado claro del suceso. La segunda pretende producir una connotación más expresiva del mensaje mediante la explotación de los mecanismos retóricos empleados previamente durante el rodaje o a posteriori, durante el montaje (ibídem). Una vez definido el objetivo de comunicación, se definen los procedimientos idóneos para organizar las sustancias informativas (figura 1):

Figura 1: Métodos asociativos y relacionales.

\begin{tabular}{|l|l|l|}
\hline PROCEDIMIENTO & \multicolumn{1}{|c|}{ MODALIDADES } & \multicolumn{1}{c|}{ FUNCION COMUNICATIVA } \\
\hline Narrar & $\begin{array}{l}\text { Lineal: Sucesión de imágenes o } \\
\text { escenas en orden cronológico. } \\
\text { Invertido: Altera el orden natural, } \\
\text { comenzando por el final y } \\
\text { finalizando con la principio. }\end{array}$ & $\begin{array}{l}\text { Narrar una acción de manera secuencial } \\
\text { o variando su orden lógico. }\end{array}$ \\
\hline Emocionar & $\begin{array}{l}\text { Paralelo: Dos o más acciones } \\
\text { independientes se desarrollan de } \\
\text { modo simultáneo. }\end{array}$ & $\begin{array}{l}\text { Genera ideas y significados asociados } \\
\text { Semejanza. } \\
\text { Contraste. }\end{array}$ \\
\hline
\end{tabular}

Fuente: Morales Morante (2012).

\subsubsection{Sujeción de la percepción espacio-temporal}

Una vez ejecutada la estrategia narrativa o emocional del mensaje, se despliega un tercer y último nivel de interacción, cuyo objetivo es reconstruir la impresión de realidad del conjunto, de toda la representación. Se contemplan aquí tres procedimientos específicos: relaciones espaciales, relaciones temporales y relaciones de apariencia visual ${ }^{6}$. En el siguiente gráfico (figura 2), puede apreciarse un esquema integral del modelo en el cual se explican los procedimientos y fases que se llevan a cabo en cada uno de los tres niveles de articulación.

6. Las relaciones espaciales configuran nuestra impresión de la representación mediante la composición visual: ubicación de la cámara, distancia, cambios de perspectiva y relación de los personajes con el fondo escenográfico. Las relaciones temporales dependen del planeamiento de rodaje y su devenir temporal que puede fortalecerse por el montaje y planeamiento estructural. Finalmente, las relaciones de apariencia visual son recursos para crear nexos u oposiciones entre unidades para dinamizar el ritmo del mensaje. Este nivel verifica el cumplimiento de los parámetros de coherencia de las reglas de rodaje desarrolladas ( $c f$. Morales Morante, 2012). 
Figura 2: Modelo de Construcción Informativa Audiovisual Eficaz (MOCIAE).

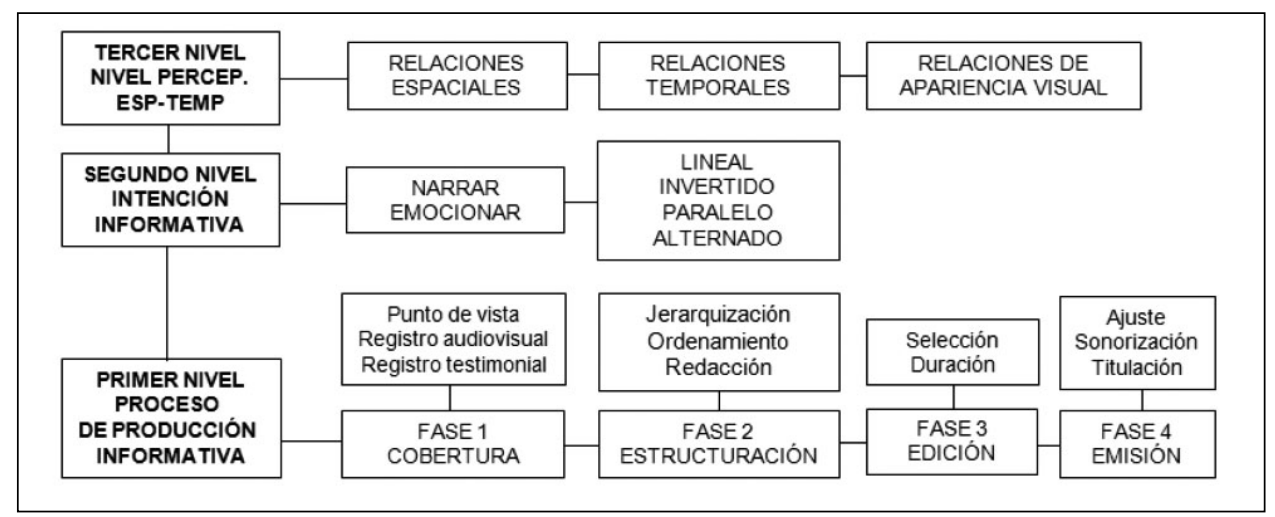

Fuente: Morales (2010).

\section{Metodología del análisis comparativo}

Una vez definidos los ámbitos y procedimientos aplicativos del (MOCIAE), veamos su funcionamiento aplicándolo al análisis del tratamiento de dos noticias emitida en dos medios de cobertura nacional: Televisión Española (TVE) y TV Perú (figura 3). La noticia seleccionada es la huelga de profesores realizada en los colegios de la ciudad de Madrid el 20 de septiembre de 2011, como protesta a los recortes presupuestales efectuados por la Comunidad de Madrid. En el caso peruano es la huelga de profesores del SUTEP, realizada el 5 de septiembre de 2012 .

Figura 3: Análisis comparativo de la noticia TVE / TV Perú.

\begin{tabular}{|c|c|c|c|}
\hline \multicolumn{4}{|c|}{ PROCESO DE PRODUCCIÓN INFORMATIVA ${ }^{7}$} \\
\hline \multirow{3}{*}{ 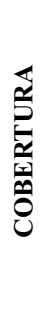 } & & Televisión Española & TV Perú \\
\hline & & $(3 ’ 05)$ & $(2 ’ 05)$ \\
\hline & $\begin{array}{l}\text { PUNTO DE } \\
\text { VISTA }\end{array}$ & $\begin{array}{l}\text { PM frontal (11"), la periodista Alba } \\
\text { Galán informando desde la Puerta } \\
\text { del Sol en Madrid con el fondo de } \\
\text { los manifestantes. } \\
\text { PM en pantalla reducida y en la } \\
\text { parte lateral (20"). Informando de } \\
\text { las estadísticas de la huelga. }\end{array}$ & $\begin{array}{l}\text { Cobertura in situ del equipo de prensa. Noticia } \\
\text { montada a posteriori. } \\
\text { PM frontal de la fachada del Ministerio de } \\
\text { Educación. } \\
\text { PG de manifestantes en las afueras del } \\
\text { Ministerio de Educación de Lima. }\end{array}$ \\
\hline
\end{tabular}

Fuente: Elaboración propia.

7. Dentro de la tabla, considerar $\mathrm{PG}=$ plano general; $\mathrm{PC}=$ plano conjunto; $\mathrm{PE}=$ plano entero; $\mathrm{PM}=$ plano medio; $\mathrm{PP}=$ primer plano y $\mathrm{PD}=$ plano detalle . 


\begin{tabular}{|c|c|c|c|}
\hline \multirow[t]{2}{*}{ 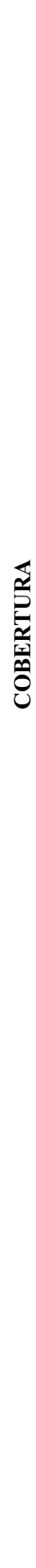 } & $\begin{array}{l}\text { REGISTRO } \\
\text { AUDIO- } \\
\text { VISUAL }\end{array}$ & $\begin{array}{l}\text { 1. PG en ángulo picado de la } \\
\text { multitud de huelguistas desfilando } \\
\text { por la Puerta del Sol. } \\
\text { 2. PE paso de manifestantes por el } \\
\text { costado de la cámara. } \\
\text { 3. PG lateral de los manifestantes. } \\
\text { 4. PE Panorámica de la gente } \\
\text { pasando, banderola. } \\
\text { 5. PD zoom in de la banderola. } \\
\text { 6. PM de una pareja de chicas } \\
\text { protestando. } \\
\text { 7. PG manifestantes por debajo la } \\
\text { voz en off de ambos reporteros. } \\
\text { 8. PM de cuatro testimonios. } \\
\text { 9. PG imágenes de interior de } \\
\text { colegio, aulas vacías o con pocos } \\
\text { alumnos. } \\
\text { 10. PG del frontis de un colegio. } \\
\text { 11. PC entrada de unos pocos } \\
\text { alumnos al colegio. } \\
\text { 12. PD imágenes de pies y espaldas } \\
\text { de alumnos entrando al colegio. } \\
\text { 13. PD testimonio de Lucía Figar } \\
\text { (grabado en el plató). } \\
\text { 14. PG de grupo manifestantes } \\
\text { protestando junto con policías, } \\
\text { intentando controlar la situación. } \\
\text { 15. PP de cartel "Se Vende Escuela } \\
\text { Pública". } \\
\text { 16. PM Guardia civil deteniendo el } \\
\text { tránsito. } \\
\text { 17. PE imagen movida de la Reina } \\
\text { entrando a colegio. } \\
\text { 18. PC de manifestantes } \\
\text { protestando con ollas, panorámica a } \\
\text { policías resguardando colegio. } \\
\text { 19. PM de Esperanza Aguirre } \\
\text { conversando con Ministro de } \\
\text { Educación. } \\
\text { 20. PM de Ángel Gabilondo. } \\
\text { 21. PG de manifestantes. }\end{array}$ & $\begin{array}{l}\text { 1. PP de las ventanas exteriores del Ministerio } \\
\text { de Educación de Lima. Zoom in a PP del } \\
\text { ventanal roto. } \\
\text { 2. PG de la fachada con esquirlas de cristales rotos. } \\
\text { 3. PP de cristal roto de la ventana de la segunda planta. } \\
\text { 4. PG de manifestantes gritando en el } \\
\text { frontis exterior del Ministerio de Educación } \\
\text { enfrentándose a un grupo de policías con } \\
\text { escudos de defensa. } \\
\text { 5. PP de manifestantes lanzando arengas frente a } \\
\text { las cámaras de televisión. } \\
\text { 6. PP de hombre agazapado tras un arbusto coge } \\
\text { un objeto contundente para lanzarlo a los policías. } \\
\text { 7. PG de la manifestación desde la segunda } \\
\text { planta del Ministerio. Gente gritando. } \\
\text { 8. PC del interior de una oficina del Ministerio. } \\
\text { Se escuchan ruidos de las piedras golpeando } \\
\text { sobre las ventanas. Imagen movida y oscura. Se } \\
\text { escuchan ruidos de voces. } \\
\text { 9. PP declaraciones del Viceministro de } \\
\text { Educación. } \\
\text { 10. PP de manifestante caminando y mirando } \\
\text { hacia la cámara con actitud amenazadora. } \\
\text { 11. PM del viceministro señalando a los } \\
\text { periodistas los destrozos en las ventanas. } \\
\text { 12. PP declaraciones del Viceministro de } \\
\text { Educación. } \\
\text { 13. PG imagen movida de la cámara captando } \\
\text { a los manifestantes en los exteriores del } \\
\text { Ministerio. } \\
\text { 14. PG imagen movida de manifestantes } \\
\text { atacando a los periodistas. Los policías intentan } \\
\text { evitar el ataque. } \\
\text { 15. PG de la manifestación desde la segunda } \\
\text { planta del Ministerio. Gente gritando } \\
\text { 16. PP declaraciones del Viceministro de } \\
\text { Educación. } \\
\text { 17. PG de los manifestantes. } \\
\text { 18. PP de manifestante pintando una pared. } \\
\text { 19. PP de manifestante caminando y mirando } \\
\text { hacia la cámara con actitud amenazadora. } \\
\text { 20. PG de la policía enfrentándose a los } \\
\text { manifestantes. }\end{array}$ \\
\hline & $\begin{array}{l}\text { REGISTRO } \\
\text { TESTIMO- } \\
\text { NIOS }\end{array}$ & $\begin{array}{l}\text { - Stand up de la reportera } 1 . \\
\text { - Voz en off reportera } 1 . \\
\text { - Voz en off reportera } 2 . \\
\text { - Nadia (profesora). } \\
\text { - Álvaro Salgado (profesor). } \\
\text { - Amparo Andrés (madre). } \\
\text { - Ángeles Real (madre). } \\
\text { - Lucía Figar (Consejera de } \\
\text { Educación). } \\
\text { - Esperanza Aguirre (Presidenta de } \\
\text { la Comunidad de Madrid). } \\
\text { - Voz off reportera. } \\
\text { - Ángel Gabilondo (Ministro de } \\
\text { Educación). } \\
\text { - Voz off de reportera. }\end{array}$ & $\begin{array}{l}\text { - Voz off reportero. } \\
\text { - Declaraciones del Viceministro de } \\
\text { Educación. } \\
\text { - Voz off reportero. } \\
\text { - Declaraciones del Viceministro de } \\
\text { Educación. } \\
\text { - Voz off reportero. } \\
\text { - Declaraciones del Viceministro de } \\
\text { Educación. } \\
\text { - Voz off reportero }\end{array}$ \\
\hline
\end{tabular}




\begin{tabular}{|c|c|c|c|}
\hline \multirow{2}{*}{ 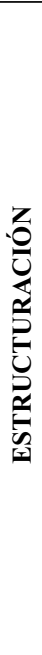 } & $\begin{array}{l}\text { SENTIDO } \\
\text { NOTICIOSO }\end{array}$ & $\begin{array}{l}\text { - Transmitir la impresión del } \\
\text { carácter multitudinario de la } \\
\text { manifestación. } \\
\text { - Muchas personas de diferentes } \\
\text { edades. } \\
\text { - Tratamiento informacional- } \\
\text { testimonial-multiperspectiva } \\
\text { de las personas afectadas y con } \\
\text { intervención significativa del } \\
\text { reportero. }\end{array}$ & $\begin{array}{l}\text { - Transmitir la impresión violenta de la actitud } \\
\text { de los manifestantes frente al local del } \\
\text { Ministerio y la prensa. } \\
\text { - Tratamiento informativo basado en el hilo } \\
\text { conductor del resultado de las protestas } \\
\text { sindicales. No hay intervención activa del } \\
\text { reportero solo la narración off explícita } \\
\text { de los hechos en función del valor } \\
\text { comunicativo de la imagen y las acciones de } \\
\text { los manifestantes en distintos lugares. } \\
\text { Da un peso importante al testimonio oficial } \\
\text { del viceministro. }\end{array}$ \\
\hline & $\begin{array}{l}\text { ORDEN } \\
\text { REDACCIÓN }\end{array}$ & $\begin{array}{l}\text { - Preferencia a la información de } \\
\text { última hora en directo. } \\
\text { - Síntesis de la jornada de paro. } \\
\text { - Valor importante a los testimonios } \\
\text { de los profesores huelguistas. } \\
\text { - Hilo conductor entre el enlace en } \\
\text { directo y la jornada de la mañana } \\
\text { por el periodista. }\end{array}$ & $\begin{array}{l}\text { - Preferencia de la información de resumen de } \\
\text { la jornada en un lugar determinado. } \\
\text { - No hay evidencias de una transmisión en } \\
\text { directo, solo diferido. } \\
\text { - Síntesis de la jornada en un espacio } \\
\text { delimitado (exteriores del Ministerio) y de } \\
\text { cómo afecta al rompimiento del orden y } \\
\text { agresión a los locales institucionales. }\end{array}$ \\
\hline \multirow{2}{*}{ 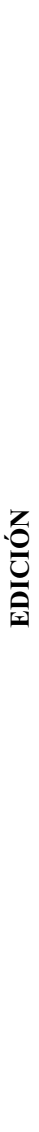 } & SELECCIÓN & $\begin{array}{l}\text { - Encuadres principalmente amplios } \\
\text { para mostrar la dimensión de } \\
\text { la protesta y los lemas de los } \\
\text { carteles y las camisetas de los } \\
\text { manifestantes. } \\
\text { - Las imágenes de los alumnos } \\
\text { no son frontales, los muestran } \\
\text { de forma subliminal o lateral: } \\
\text { espaldas y pies, para no dejar ver } \\
\text { los rostros. } \\
\text { - Predominio de planos generales } \\
\text { para manifestantes, de conjunto } \\
\text { para las aulas, medios y cortos } \\
\text { para los testimonios. } \\
\text { - Los movimientos de cámara } \\
\text { no son muy frecuentes, } \\
\text { principalmente descriptivos. }\end{array}$ & $\begin{array}{l}\text { - Encuadres principalmente amplios. Uso } \\
\text { extenso de movimientos de cámara: } \\
\text { panorámicas y zoom in realizados con } \\
\text { cámara portátil al hombro. } \\
\text { - Encuadres movidos y que dan la sensación } \\
\text { de implicación del reportero en la acción, } \\
\text { como testigo de las actitudes violentas y } \\
\text { descontroladas de los manifestantes. Uso } \\
\text { expresivo resaltando la actitud defensiva } \\
\text { de la acción policial y violenta de los } \\
\text { manifestantes. } \\
\text { - Hay unos pocos planos estáticos pero con } \\
\text { una fuerte dinámica interna, mostrando } \\
\text { las reacciones de los manifestantes. Estos } \\
\text { quedan limitados a las acciones controladas } \\
\text { de los testimonios del viceministro. }\end{array}$ \\
\hline & DURACIÓN & 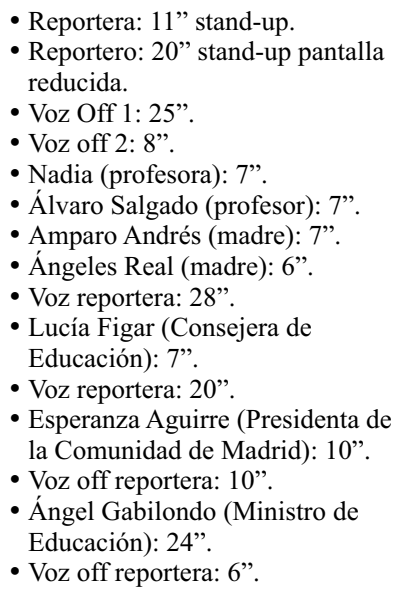 & $\begin{array}{l}\text { - Voz en off: 27". } \\
\text { - José Martín Vegas (Viceministro de Gestión } \\
\text { Pedagógica): } 11 " . \\
\text { - Voz en off: 20". } \\
\text { - José Martín Vegas (Viceministro de Gestión } \\
\text { Pedagógica): 15". } \\
\text { - Voz en off: 35". } \\
\text { - José Martín Vegas (Viceministro de Gestión } \\
\text { Pedagógica): 10". } \\
\text { - Voz off cierre: } 20 "\end{array}$ \\
\hline
\end{tabular}




\begin{tabular}{|c|c|c|c|}
\hline \multirow{3}{*}{$\frac{\sum_{0}}{0}$} & $\begin{array}{l}\text { AJUSTE } \\
\text { TEMPORAL } \\
\text { DEFINITIVO }\end{array}$ & $\begin{array}{l}\text { - Entrada stand-up: } 54 ", \\
\text { - Cuerpo reporte: 2'05". } \\
\text { - Cierre: 6". }\end{array}$ & $\begin{array}{l}\text { - Entrada (voz off): 27”. } \\
\text { - Desarrollo: 1'30". } \\
\text { - Cierre: 8". }\end{array}$ \\
\hline & $\begin{array}{l}\text { TITULA- } \\
\text { CIÓN }\end{array}$ & $\begin{array}{l}\text { - Alba Galán: Madrid. } \\
\text { - Profesores de Madrid en huelga: } \\
\text { padres, alumnos y profesores } \\
\text { protestan por recortes. } \\
\text { - Nadia (profesora). } \\
\text { - Álvaro Salgado (profesor). } \\
\text { - Amparo Andrés (madre). } \\
\text { - Ángeles Real (madre). } \\
\text { - Lucía Figar (Consejera de } \\
\text { Educación). } \\
\text { - Esperanza Aguirre (Presidenta de } \\
\text { la Comunidad de Madrid). } \\
\text { - Ángel Gabilondo (Ministro de } \\
\text { Educación). }\end{array}$ & $\begin{array}{l}\text { - Apedrean sede del Ministerio de Educación. } \\
\text { - Docentes del SUTEP serán denunciados } \\
\text { penalmente. } \\
\text { - José Martín Vegas (Viceministro de Gestión } \\
\text { Pedagógica. } \\
\text { - Equipo de TV Perú fue víctima de } \\
\text { agresiones: Dirigente de Conade estaría tras } \\
\text { actos violentos. }\end{array}$ \\
\hline & $\begin{array}{l}\text { SONORIZA- } \\
\text { CIÓN }\end{array}$ & $\begin{array}{l}\text { - Sonido ambiental elevado de la } \\
\text { manifestación. } \\
\text { - Voz en off y on de la periodista. } \\
\text { - Voz en off reportera } 2 \text {. } \\
\text { - Voces } 4 \text { testimonios. } \\
\text { - Voz reportera } 2 \text {. }\end{array}$ & $\begin{array}{l}\text { - Sonido ambiental elevado de la } \\
\text { manifestación y sobretodo de los disturbios } \\
\text { y bombardas de la policía. } \\
\text { - Voz en on de la periodista. } \\
\text { - Testimonio del Viceministro de Gestión } \\
\text { Pedagógica, José Martín Vegas. }\end{array}$ \\
\hline
\end{tabular}

\section{Análisis comparativo}

El análisis de ambas noticias muestra diferencias importantes en el tratamiento del contenido, la articulación expresiva del mensaje, así como del sentido que finalmente transmiten ambos discursos. Veamos en qué aspectos puntuales se advierten las diferencias con mayor claridad.

\subsection{Fase de producción informativa: Cobertura}

\subsubsection{Punto de vista}

La localización predominante de la cámara es frontal a la acción que se representa. En el caso de TVE, se aprecia únicamente una toma en un plano medio conjunto de la presentadora desde la Puerta del Sol, en Madrid. Muestra a la periodista en un plano medio conjunto, mientras que hacia el fondo vemos la multitud de manifestantes rodeados de pancartas alusivas a la marcha. Luego de 11 segundos de relato de la periodista, su encuadre se reduce y se ubica en la parte inferior izquierda de la pantalla, mientras que la imagen de la manifestación se agranda viéndose en plano general a toda pantalla. El plano de tipo descriptivo es empleado para autenticar la presencia del periodista en el lugar de la noticia.

En TV Perú, el abordaje del material periodístico es bastante más acotado y centra la atención informativa en las manifestaciones de protesta que se producen puntualmente en las afueras de la sede central de Ministerio de Educación de Lima-Perú. La representación 
es menos planificada, no deja en evidencia la presencia del reportero en el lugar de los hechos como en TVE, que sí incluye un enlace o un mecanismo de conexión entre el periodista y el público. Aquí se trata directamente de un material editado a posteriori de su realización. Un detalle importante y que marca la diferencia de enfoque es que en este caso todo el desarrollo explicativo del suceso está hecho desde la perspectiva del periodista, mediante una voz en off que se fragmenta en cuatro intervenciones, sin dar ningún margen de intervención testimonial de los manifestantes implicados en la protesta.

\subsubsection{Registro audiovisual}

El planteamiento de la captación de imágenes viene condicionado fuertemente por las características propias de los espacios relacionados con la información principal: calles, plazas, barullos, escuelas, testimonios. Los planos generales tienen una función descriptiva y mayormente se centran en relatar la información que sucede en exteriores: maestros marchando, gritando, haciendo ruido, llevando pancartas. Se perciben combinaciones de ambos contenidos para describir los detalles relevantes. Los planos más reducidos se usan para mostrar fachadas de colegios, grupos de alumnos que entran y salen. Los menores son representados con imágenes parciales de alumnos (de espaldas, pies, incluso un poco borrosas). También se ven planos medios de maestros que se encuentran tras las rejas, filtrando el acceso a los locales. En los interiores se graban las aulas con escaso alumnado e incluso vacías.

En la cobertura de TVE encontramos distintas imágenes acompañadas de movimientos de cámara (panorámicas desde planos cortos de las carpetas hasta el atril del profesor o de la entrada de los colegios). También se emplea un video de archivo donde muestra las declaraciones de la consejera en otro espacio de la cadena. La distancia de la cámara respecto del personaje deja abierta la opción que la imagen sea un material de archivo. El trabajo de producción es bastante completo y diversificado.

En el caso de la noticia de TV Perú, el planteamiento y enfoque informativo es ciertamente más acotado y se limita al escenario de las protestas, como reflejo claro del clima de agitación política y social que vive el sector sindical de maestros en huelga. No existe una función meramente descriptiva de la cámara, sino más bien de intentar resaltar los elementos puramente espectaculares de la protesta. El sonido ambiental de los gritos y pedradas es en este caso fundamental para hacer evidente el caos y la actitud disociadora de los manifestantes, junto con los rápidos zooms y panorámicas. El registro no busca en sí retratar la jornada de protesta desde el punto de vista del sentido social o incluso el cariz político de la manifestación: viendo como en TVE las aulas de clase y las afueras de los colegios, sino simplemente explotar la protesta y el aspecto conflictivo y sobretodo violento de los manifestantes en un espacio puntual.

De alguna manera, esto reafirma el tratamiento habitual de la televisión peruana, que no se orienta a mostrar las diferentes perspectivas y posiciones alrededor del hecho, mediante los testimonios de los afectados y de lo que sucede, sino principalmente el desborde social que subyace a la jornada de protesta. Lo hace en este caso basándose absolutamente en la 
versión oficialista, que critica explícita detalladamente lo sucedido, asociándolo incluso con grupos terroristas. No incluye testimonios de los manifestantes. Posiblemente la negativa a declarar es porque se trate del canal de Estado, que ya preconfigura una posición contraria de cualquier manifestación de reivindicación sectorial. La posición contraria a la marcha de $T V E$ es menos explícita y escueta en su argumentación, pero ligeramente en tiempo en la ubicación y orden de los testimonios condiciona a una interpretación en contra de los manifestantes.

\subsubsection{Registro de testimonios}

TVE muestra siete declaraciones y las hilvana de la siguiente forma: las cuatro primeras de forma consecutiva, una vez concluido el informe en off de la periodista. Las dos primeras son de maestros y las otras dos de madres de familia, manifestando la preocupación de las familias por el perjuicio de los recortes. Luego de todo el desarrollo, se insertan los otros tres: Lucía Figar (Consejera de Educación), Esperanza Aguirre (Presidenta de la Comunidad de Madrid) y Ángel Gabilondo (Ministro de Educación). Son las voces oficiales que critican la acción de protesta. Vemos que en ningún momento aparece el testimonio de algún representante sindical. Con ellos se cierra la noticia.

En el caso de TV Perú sólo observamos y en tres intervenciones el testimonio del Viceministro de Gestión Educativa, criticando duramente las demandas, mostrando directamente los daños ocasionados y señalando claramente las medidas legales que adoptará su portafolio en respuesta a los desmanes ocasionados por la turba de huelguistas.

\subsection{Fase de producción informativa: Estructuración}

\subsubsection{Sentido noticioso}

El diseño de TVE propone un esquema de tratamiento integral sintético de la huelga. Le da un valor preponderante a las acciones de los manifestantes y la visualización de una gran multitud respaldándola. Muestra diferentes puntos de vista de las partes involucradas, pero dando una preferencia especial al enfoque político alrededor de la protesta y sus efectos directos en la acción política de la Comunidad. Muestra a Lucía Figar, Esperanza Aguirre y Ángel Gabilondo. La multiperspectiva y cronología de los hechos es clara para transmitir una impresión de objetividad, de retrato naturalista de los hechos. No obstante, la elección de los testimonios determina una lectura conciliadora que se formula con claridad en las declaraciones del ministro. No se muestra a los representantes sindicales que en el contexto español tienen un rol social importante en este tipo de situaciones.

En TV Perú, el diseño informativo es más reduccionista, esquemático y sujeto a la acción de enfrentamiento civil, policial y muy especialmente ante la presencia de los periodistas del canal estatal. De hecho el elemento clave es la diferente actitud para asumir la situación que asumen los huelguistas españoles y los peruanos. En el primer caso se observa una postura de protesta y defensa de una causa colectiva y social por la pérdida de derechos, de recursos para hacer una buena labor, pero que se traduce en una protesta, en pacífica. A lo sumo llega a sugerir "conatos" 
de conflicto en momentos de tensión. En el caso de los huelguistas peruanos, la actitud de partida es bastante diferente. Lleva detrás un componente político ideológico más evidente. Es al tiempo más individual y fundamente la protesta en una necesidad de aumento de sueldos y pensiones, pero no incluye las pérdidas en la calidad del servicio. Los manifestantes son de hecho menos tolerantes y parten con una actitud agresiva y de rechazo radical a las fuerzas del orden que va hasta la irreverencia, incluso antes que ellos hayan intervenido.

Esta diferencia del modelo de colectivos sindicales, determina totalmente el enfoque del acontecimiento, y los componentes informativos que marcan la evolución de la noticia y el abordaje que de ella efectúan ambos reporteros. En el caso peruano la periodista no se implica en la situación, sino detalla y explica lo que ya se muestran las imágenes. También la reacción de los huelguistas ante los periodistas de la televisión del Estado, añade un ingrediente más para la reacción violenta que es aprovechada indirectamente por los periodistas para desacreditarlos, poniendo implícitamente en debate el tema de la libertad de manifestación y de información.

\subsubsection{Ordenamiento y redacción}

En ambos casos se otorga preferencia a los elementos descriptivos iniciales narrados mediante la voz en off, aunque el tiempo de la presencia del reportero sea notoriamente desigual. TVE concentra el peso en los datos cronológicos en tres secciones. La primera muestra la retransmisión en directo de cómo se va desarrollando la protesta a finales de la tarde. Luego el resumen de lo que ha sucedido durante el día. Los testimonios y finalmente la previsión para los días siguientes. La introducción de fragmentos de voz en off tiene un uso sintáctico, para explicar alguna parcela informativa no explicitada con las imágenes.

La noticia de TV Perú es un tanto más breve, pero desarrolla un tratamiento cronológico integral del hecho mostrado en dos bloques. La rotura de los cristales y la reacción institucional ante la actitud violenta de los huelguistas. El estilo de redacción intenta simular de alguna manera una narración espontánea en directo, para darle mayor énfasis a la acción de la cámara y apoyándose en la fuerza comunicativa del sonido ambiental directo.

\subsection{Fase de producción informativa: Edición}

\subsubsection{Selección}

TVE plantea el esquema de montaje recurriendo mayoritariamente un encuadres amplios y frontales para mostrar la dimensión espectacular de la marcha. Se aprecia una gran multitud de seguidores. En la primera parte, los planos elegidos reflejan una perspectiva variada. Las multitudes, pancartas se muestran en planos largos, pero hay combinaciones hacia planos más cercanos que muestran detalles expresivos de los manifestantes: rostros, carteles, ollas y pitos haciendo ruido. En la sección del resumen de la jornada, también hay algunas imágenes próximas de multitud, pero en menor número, que se emplean, al parecer para establecer un nexo hacia la jornada de la mañana. 
Los contenidos visuales si bien son enlazados mediante una toma general de la marcha, son bastante distintos porque ahora la preferencia visual gira alrededor de las aulas y alumnos. En esta sección los planos son disímiles. Mientras los acontecimientos de exteriores se representan mediante planos amplios y abiertos para evidenciar la poca presencia de alumnos y profesores. Las necesarias imágenes de alumnos se hacen en planos más cortos, pero evitando explícitamente que identifiquemos sus rostros, encuadres laterales o subjetivos. Para explicar el contexto educativo, se muestran imágenes de objetos como libros, cuadernos o las mochilas de los alumnos.

En TV Perú, la edición es menos cuidadosa, probablemente por la carencia de material audiovisual disponible, que finalmente acaba produciendo una pieza de menor duración y peso dentro de la estructura del informativo. El hilo conductor está marcado por el material registrado por la cámara y los tres fragmentos con la intervención del viceministro. Los planos son principalmente largos. Abundan los movimientos de cámara y de lente para encuadrar mínimamente acciones móviles con escasa planificación. Las tomas estáticas son reducidas y se fijan por la acción y reacción de los personajes en el escenario del conflicto. Aquí hay diferencias sensibles en cuanto al espectro del material producido y montado. Mientras en la noticia de TVE abundan los encuadres controlados, fijos para producir estructuras métricas más estables e incluso sobrias de la representación, en el caso TV Perú, esto es prácticamente imposible, pues la noticia se produce únicamente en campos exteriores en un conflicto directo desde una posición de masa movible y algunas reacciones policiales esporádicas.

Estos hechos hacen inviable plantearse otro esquema de montaje que no sea el que finalmente se muestra al espectador. Las secciones más controladas corresponden a las imágenes del viceministro mostrando los daños y sus declaraciones en el espacio de la sala de prensa. No se incluyen ni como imágenes de apoyo tomas de alumnos, profesores y aulas en su espacio natural. Inclusive el texto final hace mención explícita a que los profesores han cambiado las pizarras por las piedras.

\subsubsection{Duración}

Se observa un mayor trabajo de fragmentación y estructuración en la noticia de TVE comparada con la de TV Perú. Reportera: 11" stand-up; reportero: 20" stand-up pantalla reducida; voz off 1: 25"; voz off: 2: 8"; Nadia (profesora): 7"; Álvaro Salgado (profesor): 7"; Amparo Andrés (madre): 7"; Ángeles Real (madre): 6"; voz reportera: 28"; Lucía Figar (Consejera de Educación): 7"; voz reportera: 20"; Esperanza Aguirre (Presidenta de la Comunidad de Madrid): 10"; voz off reportera: 10"; Ángel Gabilondo (Ministro de Educación): 24"; voz off reportera: 6".

En TV Perú distinguimos: voz en off: 27"; José Martín Vegas (Viceministro de Gestión Pedagógica): 11"; voz en off: 20"; José Martín Vegas (Viceministro de Gestión Pedagógica): 15"; voz en off: 35"; José Martín Vegas (Viceministro de Gestión Pedagógica): 10"; voz off cierre: 20 ". 


\subsection{Fase de producción informativa: Emisión}

- Ajuste temporal definitivo: TVE entrada Stand up: 54"; cuerpo reporte: 2'05"; cierre: 6". En TV Perú tenemos entrada voz off: 27"; desarrollo: 1'30"; y cierre: 8".

- Sonorización: TVE recurre al sonido ambiental para recrear la manifestación que ciertamente es muy notorio en el stand-up, y los planos en exteriores, pero en estos hay un balance adecuado con las voces de los reporteros y en especial de los testimonios. En TV Perú también el sonido ambiental es fundamental para la descripción de los hechos, pero en este caso no está restringido a la voz de los cánticos de los manifestantes sino a los gritos de la multitud protestando con un cierto desorden y especialmente mostrando el sonido directo en primer plano de las explosiones, pedradas y los jaleos de la represión policial. Se ve en este segundo caso una actitud más desbordante que en el primer ejemplo, es correctamente representada con los recursos sonoros directos del registro.

- Titulación: TVE muestra un total de 9: a) Alba Galán: Madrid; b) profesores de Madrid en huelga: Padres, alumnos y profesores protestan por recortes; $c$ ) Nadia (profesora); d) Álvaro Salgado (profesor); e) Amparo Andrés (madre); f) Ángeles Real (madre); g) Lucía Figar (Consejera de Educación); $h$ ) Esperanza Aguirre (Presidenta de la Comunidad de Madrid); i) Ángel Gabilondo (Ministro de Educación). En TV Perú tenemos 4: a) Apedrean sede del Ministerio de Educación; b) Docentes del SUTEP serán denunciados penalmente; c) José Martín Vegas (Viceministro de Gestión Pedagógica); d) equipo de TV Perú fue víctima de agresiones: Dirigente de Conade estaría tras actos violentos.

\subsection{Segundo nivel: Intención informativa}

En este nivel de construcción de sentido informativo el objetivo de ambos mensajes se ciñe principalmente a la transmisión amplia, variada y correcta de la información, con un criterio basado en la actualidad, con el empleo de datos testimoniales de fuentes directamente implicadas. Sin embargo, los procedimientos de organización de los materiales audiovisuales registrados en ambas piezas dejan entrever la presencia de algunas sujeciones expositivas particulares.

La propuesta periodística de TVE plantea un esquema que puede calificarse como linealcronológico, con un desarrollo alternado basado en la pluralidad de perspectivas basada en la fusión de la cobertura de dos reporteros y el complemento testimonial de personajes directamente implicados. La primera sección de la noticia, es in situ, para dar evidencias de que están transmitiendo desde el propio lugar de los acontecimientos. Fijémonos que TVE suele hacer una cobertura en directo de la noticia del día, justamente cuando "viene produciéndose" Esto permite ofrecer al espectador "la última hora".

Luego el off pasa a narrar una breve síntesis de la jornada, apelando a un orden estrictamente secuencial: hechos, contextos y escenarios representativos. En esta sección se incluyen una 
serie de testimonios. 4 a favor de la huelga y 3 en contra. Notemos que los testimonios en contra son institucionales, tienen mayor tiempo de permanencia y son los tres testimonios finales de la noticia, lo acaba definiendo la orientación final del mensaje. Al final, y como breve colofón, la reportera cierra el informe, muy brevemente, anunciando la previsión de nuevas protestas para los próximos días.

El enfoque de TV Perú es de tipo representacional puntual, pero sólo muestra un aspecto de la noticia, sin incluir un repaso global de la jornada de huelga. En cualquier caso adolece de un componente crítico y de opinión transversal de los diferentes actores del suceso que favorezca a una altitud reflexiva imparcial del propio periodista, o que sea útil para la formación de una opinión correcta de las razones que llevan a tales protestas de la audiencia, aun cuando partan de acciones intolerables.

Posiblemente exista una suerte de temor subyacente que hace que los propios periodistas no sean críticos: de alguna manera, el silencio puede ser interpretado como una adhesión o empatía con sus conductas, por directrices editoriales, aún cuando estas puedan carecer de sustento o simplemente atenten contra las libertades de otras personas que están involucradas o no en los hechos que dan motivo a las protestas callejeras. Notemos que el único testimonio es institucional, tienen tiempo bastante largo de permanencia y define con total claridad la posición periodística del medio ante el hecho representado. Al final, y como breve colofón, el reportero cierra el informe, muy brevemente, anunciando la previsión de acciones legales inminentes, confirmando lo que ha dicho el viceministro en rueda de prensa.

\subsection{Tercer nivel: Nivel de la percepción espacio-temporal}

Podemos distinguir los siguientes aspectos relevantes. La realización de ambos mensajes se adecúa a un esquema perceptivo coherente. Las imágenes siguen siempre un esquema lógico-cronológico, dotado de continuidad espacio-temporal permanente y muestran en casi todo momento en perspectiva frontal a los personajes encuadrados a una distancia natural de relación interpersonal, equivalente al nivel de importancia que se otorga finalmente en la representación diegética.

En TV Perú, cuando esto no es posible por las dificultades de la cobertura o agitación propia del registro en directo, se muestran algunos pocos encuadres laterales, pero muy estables y que en la mayoría de las circunstancias permiten reconocer completamente al personaje. Es una especie de cuota de tratamiento profesional para compensar un posible exceso de imágenes movidas. En estos casos, la cámara produce una impresión perceptiva más naturalista espontánea y pone en realce un cierto grado de torpeza intencional operacional y de cierto descontrol justificado ante situaciones límites de movimiento o incluso de peligro de que, por ejemplo, le caiga al camarógrafo algún objeto contundente. La textura y la calidad de la imagen es más pobre.

En TVE, el diseño de composición visual mediante la cámara sugiere un modo directo y naturalista de reproducción de la escena a través de los recursos de tamaño y ángulo, preferentemente normales y de posición frontal. Los movimientos de acción interna son 
frecuentes por las características de la noticia, así como los recursos ópticos, pero cuando se emplean son solo para producir perspectiva, una sensación máxima de profundidad de campo en espacios reducidos o para adecuar el rodaje al desenvolvimiento de los actores de la noticia. En estas situaciones los camarógrafos apelan a los movimientos de cámara de corto recorrido, para que no afecten la correcta lectura de la escena e incrementar así la sensación de movimiento externo.

El esquema de montaje está basado siempre en obtener raccord y una impresión de linealidad de las acciones. El salto temporal es admitido cuando es mínimo y asumible, pero en definitiva depende de la lógica y coherencia temática del hecho, que puede admitir algún pequeño desorden en la ocurrencia real o cronológica de los registros, pero al ser desconocidos por el televidente, quedan unidos por el sentido mismo del mensaje. Igualmente, se insiste frecuentemente en remarcar la coherencia audiovisual, la imagen expresa un significado igual al canal sonoro, es reiterativo o complementario y transmite siempre un sentido unívoco de los hechos.

\section{Discusión y conclusiones}

El análisis comparativo permite visualizar elementos claros del enfoque periodístico y el estilo de tratamiento que finalmente optan ambos medios para dar a conocer un determinado hecho informativo de trascendencia social: huelga de profesores.

Hemos podido observar cómo en el caso de TVE se intenta mostrar una visión general y conjunta de la huelga, con un despliegue de cobertura bastante amplio que incluye, entre varios recursos, un enlace en directo y una "cápsula resumen" de lo más representativo acontecido en el día. El estilo de locución de la periodista es sobrio y casi pausado, para ir explicando al televidente cómo se ha desenvuelto la jornada de huelga, no solo en las calles sino en el desenvolvimiento de las actividades educativas en general e incluso actos institucionales. El uso de testimonios es bastante variado mostrando una visión múltiple de los actores involucrados en la jornada. Se aprecia un peso importante de los maestros, políticos, así como de padres de familia, preocupados por el futuro de la enseñanza pública. Sin embargo el orden, tiempo y el sentido de los testimonios acaban orientando el juicio de los hechos a favor de los políticos oficialistas y en menor medida a los manifestantes, aunque sea de una manera bastante sutil.

En TV Perú, vemos una noticia limitada a una acción violenta muy concreta que se intenta simbolizar por el periodista como una parte importante de las medidas de protesta del colectivo. No vemos que se haga una revisión panorámica de cómo se ha desarrollado la jornada en los colegios ni se ve cuál es la postura de los manifestantes, porque no son incluidos en el mensaje. Sin embargo, el componente común en ambas versiones es ver a los manifestantes frente a la policía en actitud beligerante.

Mientras en TVE sólo se ve algunos conatos, en TV Perú sí observamos enfrentamientos directos: pedradas, bombas lacrimógenas y el uso de golpes y artefactos para reprimir las acciones violentas. En cuanto al contenido, la postura institucional es mucho más explícita. 
La presencia única del viceministro en tres fragmentos de texto enfatiza fuertemente el enfoque oficial y representa una duración total de 37 ' de los 2'05" que dura la nota. Este detalle contrasta fuertemente con el despliegue y la variedad de testimonios que utiliza $T V E$, aun cuando el mensaje acabe siendo prácticamente igual.

En cuanto al tratamiento visual TVE recurre a un estilema cuasi-documentalista mediante el uso la imagen y el sonido. Hay un equilibrio intencional en la creación y montaje de planos de dimensión variada, dándoles realce al contenido inmediato de los manifestantes. El uso del sonido ambiental tiene un peso importante en toda la pieza. Vemos cómo desde el inicio el stand-up de la reportera ya lo incluye y sirve muy bien para encuadrar el carácter sonoro de la protesta callejera. También ilustra los gritos y "cacerolazos" de los manifestantes.

En el caso de $T V$ Perú, también es clave en las pedradas a los cristales y gritos de los manifestantes. En este caso le da un valor presencial al periodista e incluso de un testigo directo que muestra el acontecimiento real al espectador. Los usos de la cámara son bastante diferentes, sobre todo en las escenas en exteriores. Se aprecia un estilo intencionalmente improvisado, con encuadres movidos, registrados sin trípode y un uso intensivo de movimientos de cámara rápidos para intentar captar los momentos precisos del choque entre contrarios. Si bien hay un peso dominante de los planos secuencia, en otros instantes la representación se hace con una combinación de planos largos y cortos, variando la distancia de la cámara respecto de la escena.

Si bien en ambos casos el hecho noticioso se encuadra dentro de unas características similares, las diferencias puntuales de su intencionalidad comunicativa determinan un abordaje de cobertura, producción y montaje diferente, para (al fin y al cabo) pretender conseguir unos resultados similares de desacreditación de la protesta y de la repercusión social que finalmente alcanza.

En el caso de TVE los recursos son más compactos y variados, mientras que en TV Perú más acotados a una protesta puntual, que forma parte de una estrategia más global no presentada por los periodistas. Vemos cómo el componente cultural y actitudinal de los manifestantes es completamente distinto en ambos casos. El hecho mismo, su forma de comportarse en una situación de conflicto, su manera de asumir la protesta es marcadamente distinta.

Sin embargo, en los dos ejemplos podemos advertir un seguimiento ordenado y claro, así como el ajuste a unos mecanismos narratológicos audiovisuales que logran exponer una noticia con orden, coherencia y un ajuste a la realidad, aun cuando sean los propios procedimientos empleados en todo su planeación y realización quienes finalmente con el balance estructural y temporal, nos permitan configurar un determinado encuadre o prisma de ese hecho.

El seguimiento estricto de las normas y procedimientos de estructuración del discurso escrito $\mathrm{y}$ audiovisual son fundamentales para conseguir de la noticia televisiva un mensaje claro, directo y completo, ceñido a la evolución temporal de un hecho concreto y de la presencia de actores vinculados, habitualmente conocidos previamente por las audiencias. Pese a los cambios en los modelos productivos y el desarrollo de herramientas de realización y 
tratamiento de vídeos, las noticias para televisión, en su base más primitiva, se construyen siguiendo el mismo paradigma de organización interna de la prensa escrita, radiofónica y de las normas clásicas empleadas en la construcción de los productos argumentales.

La fórmula ternaria presentación-desarrollo-conclusión sigue funcionando plenamente como esquema base de la transmisión ordenada y correcta de la información. Y, en este caso, los recursos propios de la narrativa audiovisual la mejoran, hacen hincapié en los datos e hilvanan armónicamente los contenidos, que por su propia "ocurrencia" en la realidad pueden sucederse en espacios y tiempos diferentes. Así, los procedimientos del montaje ayudan a concatenar secciones cuya procedencia y características pueden contravenir la construcción mental de un esquema perceptivo totalmente lógico, coherente y secuencialmente cronológico, tal y como sucede en la realidad.

Por ejemplo, la inserción de títulos suplementarios, imágenes de apoyo de archivo relacionadas, la anticipación de nombres de los testigos por el texto en off, el adelantamiento intencional de la imagen o el sonido o el uso de transiciones visuales, entre otros, pueden ayudar de manera significativa a mejorar la claridad narrativa y añadirle incluso, pinceladas estético expresivas con el fin de imprimirle un sello característico a la noticia, al programa informativo y la cadena por la cual se emite.

Pero sobre la base de los hechos acontecidos se superpone el factor interpretativo, la forma de ver, la forma de contar la noticia y esos factores son los que definen su propia personalidad, marcando unas diferencias cuando la vemos tratada por dos cadenas distintas. La forma de ver, corresponde al punto de vista que asume el periodista y la cámara para construir la escena audiovisual (Entman, 1993 y 2009; Reese, 2007; Semetko y Valkenburg, 2000). Este hecho queda patente en los dos ejemplos seleccionados. La perspectiva, queda fijada por una composición dimensional, de distancia y tamaño, que depende en definitiva de la localización física del camarógrafo respecto de la situación y/o del punto de vista que desea o pueda proyectar al espectador. Este es un primer nivel. El segundo nivel está formado por la segunda estructuración que se hace a posteriori, al momento de ponderar el material, haciéndolo coincidir con el punto de vista o posicionamiento del medio, destacando unos elementos sobre otros y ordenándolos en una extensión variable de tiempo regulada por la importancia de tiempo que finalmente se decide asignarle.

Es a partir del resultado de esa segunda articulación que surgen las diferencias manifiestas entre las dos noticias. Ahí es donde se asume un rol específico y una primera instancia de filtraje que permite orientar hacia un lado u otro el significado de la imagen. La presencia de un discurso oral básico ayuda a ordenar y dirigir específicamente el sentido de la propia imagen. Esto queda más visible en el caso de TV Perú al prescindir casi por completo de los recursos testimoniales.

El análisis comparativo aplicando el MOCIAE ha sido útil para diferenciar los tratamientos empleados en ambas noticias y para diseccionar cuáles son las decisiones y estrategias llevadas a cabo en cada fase de la producción. También para conocer cuál es el sentido que producen fijándolas en un determinado orden. Por tanto, no se ha pretendido juzgar la orientación ideológica o política que puede subyacer al texto noticioso de las noticias 
emitidas por TVE o TV Perú, ni el peso de la elección de las fuentes testimoniales. Pero, la medición de su extensión, variedad datos y fuentes representan indicadores objetivos de la importancia y el enfoque que se pretende otorgar tiene un fin concreto. Este apriorismo ya forma parte de los estilos informativos marca completamente todas las etapas de trabajo.

En el presente artículo se ha intentado articular coherentemente cada una de etapas del proceso de producción de noticias para la televisión, a partir de la explotación de sus distintos recursos y métodos de trabajo, con la intención de optimizar no solo las rutinas que involucran su construcción, sino para demostrar como los periodistas y realizadores ejecutan su trabajo y le dan finalmente a sus noticias un sentido y posicionamiento que define su línea editorial. Comparar este tratamiento en dos contextos distintos nos ayuda entender los límites y las amplias posibilidades que tiene la intervención periodística sobre los hechos.

Se ha puesto a prueba el modelo aplicándolo al análisis de dos noticias emitidas por cadenas de dos países diferentes y ha permitido localizar diferencias significativas en ambos casos. El modelo pretende ser una herramienta a través del cual los profesionales y académicos del periodismo pueden localizar y enmendar las deficiencias ocurridas en las diferentes instancias de la producción y explotarlas comunicativamente en términos audiovisuales para el beneficio de la claridad informativa y la eficacia en el control de la atención, el seguimiento y el posterior recuerdo de los mensajes.

\section{Fuentes consultadas}

Amiel, V. (2005). Estética del montaje. Madrid: Abadía.

Balàzs, B. (1987). El Film: evolución y esencia de un arte nuevo. Barcelona: Gustavo Gili.

Bandura, A. (1977). "Self-efficacy: Toward a unifying theory of behavioral change". Psychological Review, núm. 84, pp. 191-215.

Cassany, D. (1987). Descriure escriure: com s'aprèn a escriure. Barcelona: Empúries.

Casasús, J. y Núñez Ladéveze, L. (1991). Estilo y géneros periodísticos. Barcelona: Ariel.

Chion, M. (2001). La audiovisión: Introducción a un análisis conjunto de la imagen y el sonido. Barcelona: Paidós.

Criger, A.; Marion, J. y Russell Neuman, W. (1994). "Interpreting visual versus audio messages in television news”. Journal of communication. Vol. 44, núm. 4, pp. 132-149.

Del Rey del Val, P. (2002). Montaje: Una profesión de cine. Madrid: Ariel.

D’ydewalle, G. y Germeys, F. (2007). "The psychology of film: perceiving beyond the cut”. Psychological Research. Vol. 71, núm. 4, pp. 458-466. 
Fernández Díez, F. y Martínez Abadía, J. (1998). Manual básico de lenguaje y narrativa audiovisual. Barcelona: Paidós.

Entman, R.

_(2009). Projections of power: Framing news, public opinion, and US foreign policy. Chicago: University of Chicago Press.

_(1993). "Framing: Toward clarification of a fractured paradigm". Journal of Communications. Vol. 43, núm. 4, pp. 51-58.

Fernández del Moral, J. (1993). Fundamentos de la información periodística especializada. Madrid: Síntesis.

Field, S. (2001). El Manual del guionista: ejercicios e instrucciones para escribir un buen guión paso a paso. Madrid: Plot Ediciones.

Goffman, E. (1974). Frame analysis: An essay on the organization of experience. Nueva York: Harper \& Row.

Huertas, A. y Perona, J. (1999). Redacción y locución en medios audiovisuales. Barcelona: Bosch.

Lázaro, F. (1993). "Prólogo”. En Libro de Estilo de ABC. Barcelona: Ariel.

López, A. (1996). Escritura e información. La estructura del lenguaje periodístico. Madrid: Cátedra.

Mann, W. y Thompson, S. (1988). "Rhetorical structure theory: Toward a functional theory of text organization". Text. Vol. 8, núm. 3, pp. 243-281. Extraída el 28/IV/2014 desde http://www.cis.upenn.edu/ nenkova/Courses/cis700-2/rst.pdf

Martínez Albertos, J. (1989). El lenguaje periodístico. Estudios sobre el mensaje y la producción de textos. Madrid: Paraninfo.

Mas Manchón, L. (2011). "Modelo superestructural de la noticia en Televisión”. Estudios sobre el Mensaje periodístico. Vol. 17, núm. 1, pp. 95-116.

Mascelli, J. (1998). Los cinco principios básicos de la cinematografía. Manual del montador de cine. Barcelona: Bosch.

May, J. y Barnard, P. (2003). “Using Film Cutting Techniques in Interface Design”. HumanComputer Interaction. Vol. 18, núm. 4, pp. 325-372.

Metz, C. (2002). Ensayos sobre la significación en el cine. Barcelona: Paidós.

Millerson, G. (2001). Realización y producción en televisión. Madrid: Instituto Oficial de Radio y Televisión. 
Mitry, J. (2002). Estética y psicología del cine. Barcelona: Siglo XX.

Morales, F.

_(2010a). "Forma y estructura discursiva de la noticia audiovisual. Una propuesta para su estudio y análisis de sus efectos de sentido". Perspectivas de la Comunicación. Vol. 3, núm. 1, pp. 7-19.

_(2010b). Diseño de un modelo para el estudio del impacto perceptivo del overlapping o encabalgamiento audiovisual [tesis doctoral]. Barcelona: Universidad Autónoma de Barcelona.

_(2000). Teoría y práctica de la edición en video. Lima: Universidad de San Martín de Porres.

Morales Morante, L. (2012). "Estructura y sentido de la noticia televisiva: parámetros para la construcción y el análisis del mensaje en el entorno audiovisual". Estudios sobre el mensaje periodístico. Vol. 18, núm. 2, pp. 805-821.

Prado, E. (1981). Estructura de la información radiofónica. Barcelona: ATE.

Quinquer, L. (2001). El drama de escribir un guión dramático. Barcelona: Nuevas Ediciones de Bolsillo.

Reese, S. (2007). "The framing project: A bridging model for media research revisited". Journal of Communication. Vol. 57, núm. 1, pp. 148-154.

Reisz, K. y Millar, G. (2003). Técnica del montaje cinematográfico. Madrid: Plot.

Rodero, E. (2003). Locución radiofónica. Madrid: Instituto Oficial de Radio y Televisión.

Sádaba, T. (2001). “Origen, aplicación y límites de la 'Teoría del Encuadre' (Framing) en Comunicación”. Comunicación y Sociedad. Vol. XIV, núm. 2, p. 143-175.

Sadosky, M. y Paivio, A. (2001). Imagery and text. A dual coding Theory of reading and writing. Nueva Jersey: Lawrence Erlbaum Associates.

Sánchez, R. (2003). Montaje cinematográfico: arte de movimiento. Buenos Aires: La Crujía.

Scheufele, D.

_(2000). "Agenda-setting, priming, and framing revisited: Another look at cognitive effects of political communications". Mass Communication \& Society. Vol. 3, núm 2-3, pp. 297-316.

_(1999). "Framing as a theory of media effects". Journal of Communication. Vol. 49, núm. $\overline{1}$, pp. 103-122.

Scheufele, D. y Tewksbury, D. (2007). "Framing, agenda setting, and priming: The evolution of three media effects models". Journal of Communications. Vol. 57, núm. 1, pp. 9-20. 
Semetko, H. y Valkenburg, P. (2000). "Framing European Politics: A content analysis of press and television news". Journal of Communication. Vol. 50, núm. 2, pp. 93-109.

Taboada, M. y Mann, W. (2005). "Rhetorical Structure Theory: looking back and moving ahead”. Discourse Studies. Vol. 8, núm. 3, pp. 423-459.

Tankard, J. (2001). “The empirical approach to the study of Media Framing”, pp. 95-106.

En Reese, S.; Gandy, O. y Grant, A. (eds.). Framing public life. Nueva Jersey: Erlbaum.

Van Dijk, T. (1990). La noticia como discurso: comprensión, estructura y producción de la información. Barcelona: Paidós.

Westley, B. y MacLean, M. (1957). “A Conceptual Model for Communications Research”. Journalism Quarterly, núm. 34, pp. 31-38.

Wurtzel, A. (1983). Television production. Nueva York: McGraw-Hill. 